\title{
A STUDY OF RISK FACTORS IN STROKE PATIENTS IN GOVT., GENERAL HOSPITAL, KURNOOL, A.P.
}

\author{
B.S. Isaac Ebenezer ${ }^{1}, \mathrm{R}$. Elizabeth Rani²
}

\section{HOW TO CITE THIS ARTICLE:}

BS Isaac Ebenezer, R. Elizabeth Rani. "A study of risk factors in stroke patients in govt., general hospital, Kurnool, A.P.”. Journal of Evolution of Medical and Dental Sciences 2013; Vol. 2, Issue 43, October 28; Page: 8333-8338.

\begin{abstract}
A study was undertaken on 50 patients admitted in Govt. General Hospital, Kurnool with acute cerebrovascular disease by using a pretested questionnaire. Parameters studied were age, sex, blood pressure, diabetes mellitus, smoking, alcohol, and hypercholesterolemia. 30(60\%) patients gave the history of hypertension in the past and were on treatment, apart from 10 more patients recorded a high blood pressure $(>140 / 90)$ at the time of admission, making a total of $40(80 \%)$ patients with hypertension. Out of 40 cases of hypertension, $30(75 \%)$ had cerebral infarction and $10(25 \%)$ had cerebral hemorrhage. 18 patients gave the history of diabetes, and 14 more had blood sugar more than $140 \mathrm{mgs} \%$ at the time of admission, making a total of 32(64\%). Out of 30 cases of diabetes, $20(66 \%)$ had infarction and 10(33\%) had hemorrhage. $25(50 \%)$ patients were in the habit of smoking at a frequency of 5-25 cigarettes per day. Out of 25 patients with smoking $20(80 \%)$ had infarction and $5(20 \%)$ had hemorrhage. 16 patients gave the history of alcoholism. Out of which 7(43.7\%) had infarction and 9(56.3\%) had hemorrhage. Out of the 25 patients with smoking habit 16 were hypertensive patients and 9 patients revealed raised serum cholesterol. Out of 16 patients with alcohol habit, 11 were hypertensive patients and 5 had raised serum cholesterol. Out of these 11 hypertensive patients 5 had infarction and 6 had hemorrhage. The 5 patients who had raised cholesterol 3 had infarction and 2 had hemorrhage. Out of the 32 diabetes cases, 21 had hypertension, and 11 had raised serum cholesterol. Out of 21 hypertensive's, 12 had infarction and 9 had hemorrhage. Out of 11 patients who had raised serum cholesterol, 8 had infarction and 3 had hemorrhage.
\end{abstract}

INTRODUCTION: Stroke is defined as a focal neurological deficit of sudden onset due to nontraumatic vascular lesion. Stroke rank first in frequency and important among all neurological disorders of adult life. it is the most frequent cause of death of neurological origin. Almost all elderly people have blockage of some small arteries in the brain and $10 \%$ of the people have enough blockage to cause serious disturbance of brain function, a condition called stroke. If for any reason the blood flow is critically reduced below $15 \mathrm{ml}$ per $100 \mathrm{~g}$ per min. the resulting ischemia with hypoxia, when sufficiently prolonged, may cause death of neurons and glial infarction (1).

Strokes are classified into:

1. Ischemic strokes:

a) with cerebral infarction

b) with cerebral ischemia

2. Hemorrhagic strokes

3. Strokes of undetermined origin

Multiple risk factors are involved in the pathogenesis of stroke. The present study was undertaken to know the various risk factors involved in the causation of stroke.

AIM OF THE STUDY: To study the risk factors involved in the causation of stroke. 
MATERIALS AND METHODS: This study was conducted in the year 2007.

Information collected from the patients/patients attendants by using a pretested questionnaire and from the case sheets.

Study design: Descriptive study

Study subjects: 50 patients admitted in the Govt. General hospital, Kurnool with a clinical diagnosis of acute stroke, confirmed after CT scan.

Inclusion and exclusion criteria: Patients with a clinical diagnosis of acute cerebrovascular stroke with obvious vascular cause were included in the study. Patients who had stroke for the second time were excluded from the study.

Statistical tests: Percentages, chi-square test.

RESULTS: The total number of patients with cerebrovascular disease studied was 50. Out of which 32 were males and 18 were females. The age of the patients ranged from $30-80$ years, with a mean age of 52 - 55 years. $40(80 \%)$ gave the history of hypertension. Out of which 30 (75\%) had infarction and 10 (25\%) had hemorrhage. 30 (60\%) gave the history of diabetes. Out of which 20 (66.6\%) had infarction and 10 (33.3\%) had hemorrhage. Hypercholesterolemia (serum cholesterol $>250 \mathrm{mg}$ ) was detected in 28 (56\%) patients. Out of which 15 (53.5\%) had infarction and 13 (46.5\%) had hemorrhage. Out of 50 patients, 25 patients were in the habit of regular smoking at a frequency of 5- 25 cigarettes per day. Out of these 25, 20 (80\%) had infarction and 5 (5\%) had hemorrhage. 16patients (32\%) out of total cases were alcoholics. Out of them $7(43.7 \%)$ had infarction and $9(56.3 \%)$ had hemorrhage.

Out of the 25patients with smoking habit, 16 were hypertensive patients and 9 patients revealed raised serum cholesterol. Out of 16 alcoholics, 11 had hypertension and 5 had hypercholesterolemia. Out of these 11 hypertensive patients, 5 developed infarction and 6 developed hemorrhage and out of 5 hypercholesterolemia patients 2 had infarction, and 3 had hemorrhage. Out of 32 diabetic patients 21 had hypertension and 11 had hypercholesterolemia. Out of these 21 hypertensive patients 12 had infarction and 9 had hemorrhage. Out of 11 hypercholesterolemia patients 8 had infarction and 3 had hemorrhage.

\begin{tabular}{|c|c|}
\hline Sex & No of Patients \\
\hline Male & 32 \\
\hline Female & 18 \\
\hline Total & 50 \\
\hline
\end{tabular}

Table 1: Sex wise distribution of stroke patients

\begin{tabular}{|c|c|c|}
\hline Sex & Infarction & Hemorrhage \\
\hline Male & 22 & 11 \\
\hline Female & 8 & 9 \\
\hline Total & 30 & 20 \\
\hline \multicolumn{2}{|c|}{$\mathrm{X}_{\text {idf }}=2.10$} & $\mathrm{P}<0.05$
\end{tabular}

Table 2.Showing the incidence of infarction and hemorrhage 


\section{ORIGINAL ARTICLE}

\begin{tabular}{|c|c|}
\hline Age in Years & No of Patients \\
\hline $21-30$ & 4 \\
\hline $31-40$ & 6 \\
\hline $41-50$ & 13 \\
\hline $51-60$ & 16 \\
\hline $61-70$ & 6 \\
\hline $71-80$ & 5 \\
\hline
\end{tabular}

Table 3: Age wise distribution of stroke patients

\begin{tabular}{|c|c|c|c|}
\hline \multirow{2}{*}{ Risk factor } & \multicolumn{2}{|c|}{ Type of stroke } & \multirow{2}{*}{ Total } \\
\cline { 2 - 3 } & Infarction & Hemorrhage & \\
\hline Hypertension & $30(75 \%)$ & $10(25 \%)$ & 40 \\
\hline Diabetes & $20(66.6 \%)$ & $10(33.3 \%)$ & 30 \\
\hline Raised cholesterol & $15(53.5 \%)$ & $28(46.5 \%)$ & 28 \\
\hline Smoking & $20(80 \%)$ & $5(20 \%)$ & 25 \\
\hline Alcohol & $7(43 \%)$ & $9(57 \%)$ & 16 \\
\hline
\end{tabular}

Table 4: Risk factors in stroke patients
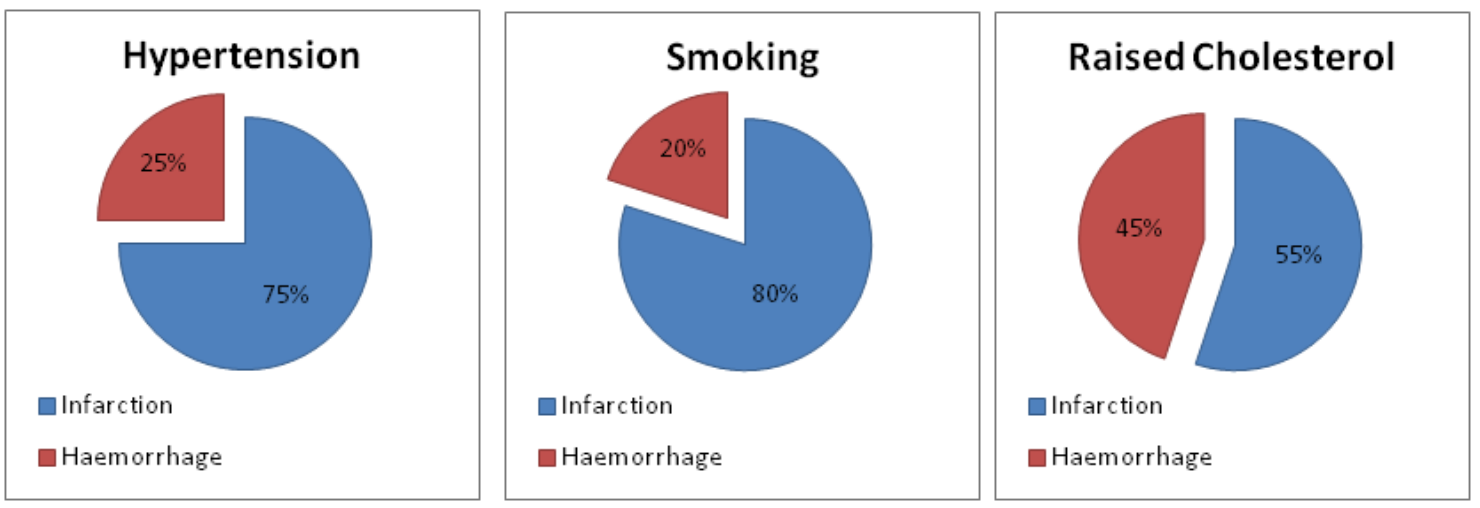

\begin{tabular}{|c|c|c|}
\hline \multirow{2}{*}{ Risk factor } & \multicolumn{2}{|c|}{ Smokers } \\
\cline { 2 - 3 } & Infarction & Hemorrhage \\
\hline Hypertension & 13 & 3 \\
\hline Hypercholesterolemia & 7 & 9 \\
\hline
\end{tabular}

Table 5: Showing relation between hypertension, hypercholesterolemia and smoking in stroke patients

\begin{tabular}{|c|c|c|}
\hline \multirow{2}{*}{ Risk factor } & \multicolumn{2}{|c|}{ Alcoholics } \\
\cline { 2 - 3 } & Infarction & Hemorrhage \\
\hline Hypertension & 5 & 6 \\
\hline Hypercholesterolemia & 2 & 3 \\
\hline
\end{tabular}

Table 6: Showing relation between alcohol, hypertension and hypercholesterolemia in stroke patients

\begin{tabular}{|c|c|c|}
\hline \multirow{2}{*}{ Risk factor } & \multicolumn{2}{|c|}{ Diabetes } \\
\cline { 2 - 3 } & Infarction & Hemorrhage \\
\hline Hypertension & 12 & 9 \\
\hline Hypercholesterolemia & 8 & 3 \\
\hline
\end{tabular}

Table 7: showing relation between diabetes, hypertension and hypercholesterolemia in stroke patients 
DISCUSSION: 29 patients out of 50(58\%) developed stroke in the middle age. Shaper A G et al in their study stated that about half of the first stroke occurs in people aged 76 years and above (2). The changes that do occur with ageing include increase in the thickness of intima due accumulation of smooth cells, leading to loss of elasticity. These vessels fail to withstand the hydrostatic pressure. The unsupported cerebral arteries may be particularly vulnerable in this regard leading to occurrence of stroke in the elderly people. Out of the 50 patients there were 32 males and 18 females with a male and female ratio of 1.8: 1. Multivariate aetiological factors are responsible for occurrence of more cases in males when compared to females.

In my study 40 (80\%) out of the total 50 cases, had hypertension, which is the leading cause of stroke. The mean arterial systolic and diastolic blood pressures are comparatively high in hemorrhage patients to that of infarction. The high blood pressure is not only a risk factor, but also a treatable etiological factor in preventing development of stroke $(3,4)$. Elevated blood pressure a precursor of stroke has been an almost universal finding in all the prospective studies $(5,6,7)$. In my study 30 patients were diabetic. Out of which 20(66.6\%) had infarction and 10(33.3\%) had hemorrhage. In some of the previous studies in a variety of population, there was an association of hyperglycemia with atherosclerotic disease, suggesting a role of hyperglycemia in stroke.

In my study out of 25(50\%) smokers, 20(80\%) had infarction and only 5(20\%) had hemorrhage, indicating that smokers at the risk of developing ischemic stroke than hemorrhagic stroke. Robert D. Abbott et al. in their study stated that cigarette smokers had 2-3 times more risk of thromboembolic or hemorrhagic stroke and cessation of smoking habit showed significant results (8). Cigarette smoking increases the risk of stroke 3 folds (9). It may be due to increase in the hemoglobin concentration and raised hematocrit as it is evident by the study of Erly et al. (10).

In my study out of $16(32 \%)$ cases of alcoholics, 9 developed intra cerebral hemorrhage, confirming the fact that alcohol is the risk factor for developing hemorrhagic stroke. Heavy drinking is known to be a risk factor for hypertension, independent of age, sex, and race (11). In my study 28(56\%) patients had raised serum cholesterol. Out of which 15 had infarction. In multiple risk factor intervention trial, the risk of death from thrombosis stroke increased significantly with increased serum cholesterol.

Hypertension and diabetes are the known risk factors for stroke. This was mentioned in the study conducted by reasons for geographic and racial differences in stroke (REGARDS), a study supported by NINDS (National Institute of Neurological Disorders And Stroke) (14). In a risk factors for stroke study (INTERSTROKE STUDY), they have identified 10 risk factors for stroke which include high blood pressure, smoking, diabetes. High blood pressure was the leading risk factor for all types of stroke (15). In a study conducted by REGARDS, between the ages of 45 and 65, African Americans have stroke mortality about 2-3 times higher than whites. In that study they did find huge differences in 2 factors. 1) High blood pressure: whites 51\% and blacks 71\%. 2) Diabetes: whites $15 \%$ and blacks $29 \%$. These risk factors may have bigger impact on blacks than whites $(16,17)$. In INTERSTROKE STUDY, 90\% of stroke cases are caused by high blood pressure, smoking, and a fat stomach. Another $10 \%$ could be attributed to diabetes. In this study they have pointed out that hypertension, smoking, diet and alcohol were the risk factors for intracerebral hemorrhage and diabetes for ischemic stroke (18). Jack V T MD, PhD of the Sunny Brook, Schulich Heart Centre at the university of Tornto, writes that these important findings should help to inform `storke prevention' strategies around the world and to reduce the global burden of stroke. 
CONCLUSIONS: Males are more susceptible to stroke when compared to females. Among the multiple risk factors, hypertension took the lead role followed by diabetes mellitus with predilection for hemorrhage and infarction respectively. Hypercholesterolemia as a risk factor along with smoking lined at third spot and showed predilection for non hemorrhagic stroke. Alcohol intake with the risk of hemorrhagic stroke stood next. The medical research council mild hypertension trial stated that treatment of mild hypertension (diastolic blood pressure $90-109 \mathrm{~mm}$. of hg) is effective in lowering the incidence of stroke (12). The best advice which can be given to patients with mild hypertension is that they should not smoke (13).

RECOMMENDATIONS: There is a need to educate the common public about the risk factors like hypertension, diabetes, high serum cholesterol, smoking and alcohol and the importance of control of hypertension, diabetes, lowering of high cholesterol and avoiding smoking and alcohol to prevent stroke.

\section{REFERENCES:}

1. DALAL PM Cerebrovascular diseases, API Text book of medicine $1997 ; 5^{\text {th }}$ ed 877

2. SHAPER AG, PHILLIPS An, POCOCK Sj, WALKER M. MACFARLANE PW Risk factors for stroke in middle aged men. BMJ 1991; 302: 111-1115

3. Hypertension detection and follow up programme co-operative group. Five year findings of the hypertension detection follow up programme III. Reduction in stroke incidence among persons with high blood pressure JAMA 1982; 247:633-38

4. THE AUSTRALIAN THE RAPEUTIC TRIAL in Mild hypertension report by management committee LANCET 1980; 1: 1261-67

5. DYKEN ML, WOLF PA, BARNETT HMJ ET AL. Risk factors in stroke a statement for physicians by subcommittee on risk factors of stroke. Stroke 1984; 15; 1105-11

6. ISBEN H, CRISTENSEN NJ, RUSMUSSEN S, HOLONGAC H, NIELSEN MD influence of alcohol intake on blood pressure. Cli Sci 1981; 61: 377

7. STEVENS RF ALEXANDER MK, A sex difference in platelet count. Indian J. Haemtol 1977; 37: 295-300

8. ROBERT D. ABBOTT, YIN YIN, DWAYNE et al; Risk of stroke in male cigarette smokers. NEJM 1986; 315: 717-20

9. BLACKWELDER WC, YANO K, RHOADS GG, KAGAN A, GORDAN T, PALESH Y. Alcohol and motality: the Honalulu heart study. Am J Med 1980; 68: 165-9

10. EHRLY AM, SCHIMPF WJ et al. 1978; 10: 245-6

11. KLATSKY AL, FRIEDMAN GD, SIEGELAUB AB et al; Alcohol consumption and blood pressure NEJM. 1977; 296: 1194-2000

12. EISEN ME, HANMOND EC, Effect of smoking on packed cell volume, red cell counts, hemoglobin and platelet counts. Can Med Assoc J 1956; 75: 520-23

13. WILSON J, LANGMAN MJS, Relation to sub acute combined degeneration of the cord to vitamin B12 deficiency. Nature (Lon) 1966; 212: 787-89

14. Michelle W Mesonnell, PhD et. Al ' physical activity frequency and risk of incident stroke in a National US study of blacks and whites' Stroke, July 18, 2013

15. Interstroke study Web MD Health News, June 18, 2010 
16. REGARDS study on stroke risk factors by Peggy Noonan, Feb 29, 2012

17. Heart disease and Stroke statistics- 2012 update. A report from the American heart foundation circulation, 2012; 125: e2-e220 (hypertension and diabetes and stroke risk).

18. Interstroke study, risk factors for stroke, NHS choice, June21, 2010.

\section{AUTHORS:}

1. B.S. Isaac Ebenezer

2. R. Elizabeth Rani

\section{PARTICULARS OF CONTRIBUTORS:}

1. Professor, Department of Community Medicine, Santhiram Medical College, Nandyal, Andhra Pradesh.

2. Assistant Professor, Department of Physiology, Kurnool Medical College, Kurnool, Andhra Pradesh.
NAME ADDRESS EMAIL ID OF THE CORRESPONDING AUTHOR:

Dr. B.S. Isaac Ebenezer,

107, A Block, Viswasai Residency,

Near Agrigold Office,

Kurnool - 518002, Andhra Pradesh.

Email - drisaac.ebenezer@gmail.com

Date of Submission: 07/10/2013.

Date of Peer Review: 08/10/2013.

Date of Acceptance: 21/10/2013.

Date of Publishing: 25/10/2013 